\title{
Aspectos quirúrgicos a considerar en el donante
}

\author{
Surgical aspects of living donation \\ José Cruz-Santiago, * Arlette Robledo-Meléndez, \\ Guillermo Meza-Jiménez, ${ }^{\ddagger}$ Lorena Noriega-Salas, ${ }^{*}$ \\ German Bernáldez-Gómez \\ * Jefe. \\ ₹ Médico especialista adscrito. \\ Unidad de Trasplantes. UMAE. Centro Médico Nacional «La Raza» IMSS.
}

\section{INTRODUCCIÓN}

El trasplante renal se considera la mejor opción terapéutica para los pacientes con enfermedad renal crónica, ya que mejora la supervivencia y calidad de vida.

En México, al igual que a nivel mundial, ha habido un incremento anual en el número de trasplantes realizados, de los cuales $70 \%$ son de donadores vivos. En 2018 se reportaron 15,072 pacientes en lista de espera y se efectuaron 3,048 trasplantes, de los cuales 2,079 eran de donante vivo, ${ }^{1}$ por lo que el donador vivo surge por necesidad. La falta de donadores vivos potenciales con las características apropiadas ha conducido a seleccionar donadores que en el pasado no habrían sido considerados como candidatos, gracias a los avances en la técnica quirúrgica y esquemas de inmunosupresión. Este grupo se conoce como fuente de donadores marginales e incluye los riñones con múltiples arterias renales. ${ }^{2}$

Aunque el trasplante renal con múltiples vasos renales se realiza en centros especializados, permanece siendo controversial y llevarlo a cabo es un reto por el riesgo de complicaciones urológicas y vasculares que pudieran presentarse. El porcentaje de pacientes que experimentan complicaciones vasculares varía de $2-23 \%,{ }^{3}$ las más frecuentes son trombosis de la arteria renal, estenosis y hemorragia. Las complicaciones ureterales representan más de $90 \%$ de los problemas urológicos después del trasplante, las cuales pueden conducir a mayor morbilidad y mortalidad. Las complicaciones urológicas más frecuentes son fuga urinaria, estenosis y reflujo, reportados en diferentes series entre $2.5-30 \%{ }^{4}$

\section{INCIDENCIA}

La incidencia de múltiples arterias renales de forma unilateral oscila entre 18 y $30 \%$ y $10 \%$ de forma bilateral en donadores renales potenciales. ${ }^{5}$

\section{EVALUACIÓN DE ANATOMÍA VASCULAR}

Antes del trasplante es OBLIGATORIO planear la técnica quirúrgica en el donador, en el injerto y en el receptor, por lo que se requiere una evaluación exhaustiva de la anatomía vascular renal del donador vivo mediante estudios de imagen.

La tomografía con reconstrucción vascular es el estudio que se utiliza de rutina, ya que genera imágenes de alta calidad que permiten valorar el tamaño renal, la anatomía del parénquima y el sistema colector, y definir la anatomía vascular.

Se sugiere evaluar la posición de la vena renal izquierda respecto a la aorta y la desembocadura de ésta hacia la cava y evitar la disección circunferencial de la aorta, ya que esta maniobra incrementa el riesgo de lesiones a la vena retroaórtica. 
Esta información puede usarse para determinar el riñón apropiado para donar. Se prefiere el riñón izquierdo por la longitud de la vena renal, por lo que generalmente se selecciona cuando una o dos arterias renales son identificadas. Puede preferirse nefrectomía derecha cuando el riñón izquierdo tiene más de dos arterias. ${ }^{6}$

\section{VARIACIONES ANATÓMICAS ARTERIALES Y VENOSAS}

Las variaciones de las arterias renales se clasifican en:

- Arterias extrarrenales.

- Hiliares o accesorias.

- Polares o aberrantes.

- Arterias de división temprana.

- Arterias renales múltiples.

- Arterias de origen anómalo.

- Emergen de la arteria mesentérica superior, celiaca e iliaca.

- Ramas aberrantes de la arteria renal.

- Gonadales y hepáticas. ${ }^{7}$

Las variaciones venosas renales pueden ser:

- Múltiples.

- Accesorias.

- Anillo renal periaórtico, donde persiste el componente anterior y posterior.

- Vena retroaórtica.

- Tipo I: persiste parte posterior con unión a la vena cava inferior en posición ortotópica.

- Tipo II: confluye a las venas lumbares ascendentes o gonadales y cava, mediante un trayecto oblicuo en un nivel más inferior, hacia L4-L5. ${ }^{8}$

\section{TÉCNICAS DE RECONSTRUCCIÓN VASCULAR DURANTE EL TRASPLANTE RENAL}

La utilización segura de los injertos con variaciones en la vasculatura renal requiere OBLIGATORIAMENTE de un equipo competente y con destreza tanto para la extracción del injerto como para su implantación.

La técnica quirúrgica del trasplante renal clásica fue descrita en 1951 y ha evolucionado durante poco más de 60 años. ${ }^{9}$ El estándar de oro en la actualidad es colocar el injerto en fosa iliaca derecha a través de un abordaje con una incisión en palo de hockey, para-rectal externa, extraperitoneal, a través de la línea de Spiegel, seccionando sólo planos aponeuróticos, con anastomosis término-lateral de la arteria renal a la arteria iliaca externa $^{10}$ y la vena renal a la vena iliaca externa, con una sutura monofilamento no absorbible 6-0.

El trasplante de injerto con múltiples arterias renales amerita una técnica fina y demandante durante la cirugía de banco y la colocación del injerto en el receptor que pudieran prolongar el tiempo de isquemia e incrementar la incidencia de necrosis tubular aguda, de la función retardada del injerto y del rechazo agudo, todos ellos asociados con mayor estancia intrahospitalaria. Se ha reportado un incremento en la posibilidad de complicaciones vasculares y urológicas, que se traduce en mayor morbilidad y pérdida del injerto en el peor de los casos. ${ }^{11}$ Algunas series han demostrado resultados similares cuando se utilizan injertos renales con arterias únicas o múltiples, o incluso con anomalías anatómicas.

La utilización segura de estos órganos requiere de gran destreza en las técnicas quirúrgicas y microquirúrgicas. Existen diferentes técnicas descritas de reconstrucción vascular en el injerto renal.

\section{CIRUGÍA DE BANCO}

Es OBLIGATORIO que la elección de la técnica de reconstrucción vascular se base en la experiencia del cirujano. Se SUGIERE realizar todas las anastomosis arteriales, incluyendo las de menor calibre.

En el caso de múltiples arterias renales existen varias técnicas quirúrgicas de reconstrucción vascular. La elección de la técnica se basará en la experiencia del cirujano buscando siempre simplificar el trasplante. ${ }^{12}$

Cuando el órgano tiene dos arterias de calibre similar puede utilizarse un parche aórtico (de Carrel) ${ }^{13}$ para mantener una boca anastomótica. Cuando no se tuviera parche aórtico, como en el caso de donante vivo, se construye un tronco único mediante una anastomosis latero-lateral en cañón de escopeta; o si están separadas, podrían anastomosarse ambas a la iliaca. ${ }^{14}$

Si las arterias son de distinto calibre, la menor se puede anastomosar a la mayor en término-lateral, con alto riesgo de obliteración vascular de ambos vasos; o si la longitud de la arteria lo permite, sobre todo en las polares inferiores o accesorias, se puede anastomosar a la arteria epigástrica inferior. ${ }^{15}$

Si el número de arterias fuera mayor de dos, las técnicas pueden combinarse.

Cuando son vasos renales de una longitud corta, puede efectuarse la anastomosis con uso de interposi- 
ción de injerto vascular autógeno (vena safena, arteria epigástrica inferior) o sintético (PTFe).

La anastomosis de la arteria renal puede realizarse a la iliaca externa o a la iliaca común, términolateral, o a la hipogástrica término-terminal. Cuando la anastomosis se realiza a la arteria hipogástrica, se liga la parte distal de ésta, en casos muy extremos podría impactar en la vasculatura del pene y la función eréctil, particularmente después de un segundo trasplante del lado contralateral, con ligadura distal de ambas hipogástricas. ${ }^{16}$ Esta complicación puede prevenirse preservando las ramas de la arteria hipogástrica y haciendo la ligadura por debajo de la bifurcación.

La anastomosis venosa suele realizarse términolateral con la vena iliaca externa o en un parche de vena cava en el caso de donante fallecido, cuando se tienen venas renales múltiples.

Es preferible realizar todas las anastomosis arteriales, aun las de pequeño calibre, para prevenir posibles complicaciones, sobre todo se sugiere la preservación o anastomosis de las polares inferiores, ya que irrigan la pelvis y uréter y su sección puede condicionar complicaciones urológicas. Si efectuar la anastomosis de las arterias polares de pequeño calibre parece muy difícil o si irriga una pequeña porción, puede perfundirse y ligarse con el riesgo de necrosis distal del uréter en caso de que sea una polar inferior, o de presentar una pequeña área de infarto en el riñón. ${ }^{9}$

Debe considerarse la longitud de las arterias o vasos a anastomosar y la adecuada posición del riñón para evitar el acodamiento de los vasos que pudiera condicionar la oclusión vascular. ${ }^{13}$

Las placas ateroscleróticas pueden incrementar el riesgo de lesión de la íntima y de la oclusión vascular. La separación de la íntima dentro del parche o en las arterias a anastomosar requiere fijación de la íntima con la placa para evitar su disección y oclusión vascular, o cortar la arteria hasta un área sin lesión, siempre y cuando la longitud del vaso lo permita.

Se requiere una disección gentil de los vasos del receptor con ligadura de los vasos linfáticos, de la misma manera que en la cirugía de banco para evitar linfoceles. Los injertos renales con múltiples arterias podrían estar asociados a mayor incidencia de linfocele. ${ }^{17}$

Para identificar de manera oportuna posibles complicaciones en injertos con vasos múltiples se SUGIERE la monitorización del injerto renal con ultrasonido Doppler en las primeras 24 horas posterior al trasplante.

www.medigraphic.com/trasplantes
Los pacientes con injertos con variantes vasculares anatómicas deberán ser monitorizados de forma estrecha, la función renal y posibles complicaciones. La ecografía Doppler es la técnica no invasiva que se utiliza para esta monitorización. Los protocolos de seguimiento posterior al trasplante varían de unos centros a otros. Por lo general, se recomienda hacer un estudio basal antes de las primeras 48 horas y posteriormente su realización estará condicionada por la evolución del órgano.

Es DESEABLE estimular el conocimiento y entrenamiento en técnicas de reconstrucción vascular y microquirúrgicas, de manera que no se descarte a un donador potencial por el hecho de presentar variantes vasculares, considerando la escasez de donadores ideales y los buenos resultados informados en las diferentes series.

Es importante no olvidar que también se requiere un equipo competente para la extracción de los riñones para evitar lesiones accidentales en éstos, especialmente en los vasos, lo que puede condicionar mayor morbilidad con repercusión en la sobrevida en el receptor y el injerto, además de dificultar la reconstrucción de los vasos y volverse un verdadero reto para la implantación.

\section{REFERENCIAS}

1. Sistema Informático del Registro Nacional de Trasplantes CENATRA. Corte al 31 de diciembre de 2018. Disponible en: www.cenatra.salud.gob.mx

2. Hasan B, Necmettin G, Muzaffer E et al. Surgical approach to cases with multiple renal arteries in renal transplantation. Urol Int. 2006; 76: 169-172.

3. Fervenza FC, Lafayette RA, Alfrey EJ, Petersen J. Renal artery stenosis in kidney transplants. Am J Kidney Dis. 1998; 31 (1): 142-148.

4. Slagt IK, ljzermans JN, Visser LJ, Weimar W, Roodnat $\mathrm{JI}$, Terkivatan T. Independent risk factors for urological complications after deceased donor kidney transplantation. PLoS One. 2014; 9 (3): e91211.

5. Hafiz SA, Imran H, Amjad AS et al. The outcome of living related kidney transplantation with multiple renal arteries. Saudi J Kidney Dis Transplant. 2013; 24 (3): 615-619.

6. Danovitch GM. Handbook of kidney transplantation. 15th. Ed. Philadelphia: Wolters Kluver/Lippincott Williams \& Wilkins; 2009.

7. Ozkan U, Oğuzkurt L, Tercan F, Kizilkiliç O, Koç Z, Koca N. Renal artery origins and variations: angiographic evaluation of 855 consecutive patients. Diagn Interv Radiol. 2006; 12 (4): 183186.

8. Mathews R, Smith PA, Fishman EK, Marshall FF. Anomalies of the inferior vena cava and renal veins: embryologic and surgical considerations. Urology. 1999; 53 (5): 873-880.

9. Kuss R, Teinturier $J$, Milliez $P$. Some attempts at kidney transplantation in man. Mem Acad Chir (Paris). 1951; 77: 755-764. 
10. Sutherland RS, Spees EK, Jones JW, Fink DW. Renal artery stenosis after renal transplantation: the impact of the hypogastric artery anastomosis. J Urol. 1993; 149: 980-985.

11. Koosha K, Mohammad AA, Alireza A et al. Renal transplantation in allografts with multiple versus single renal arteries. Saudi $J$ Kidney Dis Transplant. 2012; 23 (2): 246-250.

12. Tomic A, Milovic N, Marjanovic I, Bjelanovic Z et al. Different techniques of vessel reconstruction during kidney transplantation. Vojnosanit Pregl. 2015; 72 (7): 614-618.

13. Barlas A, Moris D, Bokos J, Zavos G. A forgotten vascular technique in renal transplantation. Vasc Endovascular Surg. 2014; 48 (3): 281-282.

14. Sarin PK, Dhanda R, Siwach V, Aggarwal B et al. Bridging of renal arteries: a simple technique for the management of double arteries in living donor renal allograft transplantation. Transplant Proc 2003; 35: 35-36.
15. Amirzargar MA, Babolhavaeji $\mathrm{H}$, Hosseini SA, Bahar HM et al. The new technique of using the epigastric arteries in renal transplantation with multiple renal arteries. Saudi J Kidney Dis Transpl. 2013; 24 (2): 247-253.

16. Beckmann JH, Jackobs S, Klempnauer J. Arterial reconstruction in kidney transplantation. Transplant Med. 2008; 20: 7-12.

17. Mazzucchi E, Souza AA, Nahas WC et al. Surgical complications after renal transplantation in grafts with multiple arteries. Int Braz J Urol. 2005; 31: 125-130.

Correspondencia:

Dra. Lorena Noriega-Salas

E-mail: noriega_lorena@ hotmail.com 